\title{
A novel monoclonal antibody against human B7-1 protects against chronic graft-vs.-host disease in a murine lupus nephritis model
}

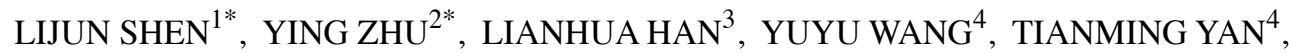 \\ YONG KONG ${ }^{4}$, SHITAO ZOU ${ }^{5}$, YUHUA QIU ${ }^{4}$ and YAN XU ${ }^{6}$ \\ ${ }^{1}$ Institutes of Biology and Medical Sciences, Medical College, Soochow University, Suzhou, Jiangsu 215123; Departments of \\ ${ }^{2}$ Clinical Laboratory and ${ }^{3}$ Cardiology, The First Affiliated Hospital of Soochow University; ${ }^{4}$ Department of Immunology, \\ Medical College, Soochow University, Suzhou, Jiangsu 215123; ${ }^{5}$ Suzhou Cancer Center Core Laboratory, Nanjing Medical \\ University Affiliated Suzhou Hospital; ${ }^{6}$ Health Management Center, The First Affiliated Hospital of \\ Soochow University, Suzhou, Jiangsu 215001, P.R. China
}

Received September 17, 2019; Accepted April 29, 2020

DOI: $10.3892 / \mathrm{etm} .2020 .9146$

\begin{abstract}
Lupus nephritis (LN) is the most common complication that causes mortality in patients with systemic lupus erythematosus. The B7-1/B7-2 and CD28/cytotoxic T-lymphocyte associated protein 4 co-stimulatory pathway serves a key role in autoimmune disease and organ transplantation. The aim of the present study was to generate and characterize a monoclonal antibody (mAb; clone 4E5) against human B7-1 and to investigate its potential use for the treatment of LN. The results demonstrated that the $4 \mathrm{E} 5 \mathrm{mAb}$ was successfully generated and able to recognize both human and mouse B7-1. After injection of this $\mathrm{mAb}$ into a mouse model with chronic graft-vs.-host disease (cGVHD)-induced lupus-like disease, the expression of CD21, CD23, CD80 and $\mathrm{CD} 86$ on $\mathrm{B} 220^{+} \mathrm{B}$-cells in the spleen, and the concentrations of serum autoantibodies and urine protein, were decreased. Direct immunofluorescence analysis of the kidneys revealed that immunofluorescence of immune complex deposits was weaker in the 4E5-treated mice and electron microscopy analyses of renal tissues indicated that pathological injury of the kidneys of 4E5-treated mice was decreased compared with that in the model control mice. The results of the present study demonstrated that inhibition of the B7-1/CD28 co-stimulatory
\end{abstract}

Correspondence to: Dr Yan Xu, Health Management Center, The First Affiliated Hospital of Soochow University, 899 Pinghai Road, Suzhou, Jiangsu 215001, P.R. China

E-mail: xuyanhmc@126.com

Professor Yuhua Qiu, Department of Immunology, Medical College, Soochow University, 199 Ren'ai Road, Suzhou Industrial Park, Suzhou, Jiangsu 215123, P.R. China

E-mail: qyh820@126.com

*Contributed equally

Key words: anti-human B7-1 antibody, lupus nephritis, chronic graft-vs.-host disease, electron microscopy, autoantibodies signaling pathway with the 4E5 mAb may represent a promising strategy to decelerate the progression of $\mathrm{LN}$ that is induced by cGVHD with potential for use in the treatment of other autoimmune diseases.

\section{Introduction}

Systemic lupus erythematosus (SLE) is an autoimmune disease that is characterized by the production of autoantibodies and immune complexes that may affect the majority of organs in the human body (1). Lupus nephritis (LN) is the most common and serious complication of SLE and is the major cause of morbidity and mortality in patients with this condition (2). A previous survey demonstrated that at least $33 \%$ of patients with SLE also have a manifestation of significant glomerulonephritis (3).

The origins of SLE remain to be fully elucidated. It is generally thought that the imbalance between cellular and humoral immunity in patients with lupus is caused by a complex interaction between genetic and environmental factors and the abnormal function of T- and B-cells that ultimately destroy normal immune tolerance mechanisms. During the initiation of a normal immune response, T-cell activation, proliferation, differentiation, cytokine secretion and avoidance of apoptosis require at least two signals (4). These signals include a specific signal that is delivered by the antigen peptide presented by the major histocompatibility complex and a non-specific signal produced by the interaction of co-stimulatory molecules (5). Co-stimulatory pathways were first proposed and confirmed on the basis of a T-cell activation double signal theory (6).

B7, an important co-stimulatory molecule that is expressed on the surface of antigen-presenting cells (APCs), exists primarily in two forms, B7-1 and B7-2. The B7 receptor on the surface of T-cells is CD28/cytotoxic T lymphocyte antigen-4 (CTLA-4) and the interaction of B7 with CD28 promotes T-cell activation, proliferation and secretion of cytokines, as well as regulating T-helper $\left(\mathrm{T}_{\mathrm{H}}\right) 1 / \mathrm{T}_{\mathrm{H}} 2$ cell differentiation and contributing to B-cell antibody production and isotype switching (7). The interaction of B7 with CTLA-4 inhibits T-cell activation and proliferation $(5,8)$. A previous study demonstrated that 
the B7-CD28 co-stimulatory signal is associated with the development of SLE (9). Therefore, blocking or weakening of the induced signal may help reduce the associated pathological damage or the development of other immune-mediated diseases.

In this present study, a monoclonal antibody (mAb) against human B7-1 was generated and characterized. The potential efficacy against SLE-related pathologies was assessed using a lupus-like nephritis mouse model, a generally-accepted animal model induced by the injection of parental BALB/c lymphocytes into BALB/c x C57BL/J6 $\mathrm{F}_{1}$ hybrids, leading to chronic graft-vs.-host disease (cGVHD) (10). This model has been previously verified and characterized as an SLE-like disease model that displays lymphoid hyperplasia, the formation of autoantibodies similar to those occurring in patients with SLE and an increased presence of renal pathologies mediated in part by immune complex formation and deposition (11).

\section{Materials and methods}

Cell lines. The human B7-1-transfected L929 cell line (L929/B7-1) and mock-transfected L929 cells (L929/mock) were previously generated and used in this present study (12). Daudi and Raji cell lines were purchased from the American type culture collection. The cell lines were cultured in RPMI-1640 medium (Gibco; Thermo Fisher Scientific, Inc.) containing $10 \%$ fetal bovine serum (HyClone; GE Life Sciences) $100 \mathrm{U} / \mathrm{ml}$ penicillin and $100 \mathrm{mg} / \mathrm{ml}$ streptomycin (Gibco; Thermo Fisher Scientific, Inc.). Cells were maintained at $37^{\circ} \mathrm{C}$ in a humidified atmosphere containing $5 \% \mathrm{CO}_{2}$.

Animals. BALB/c mice (10; female; age, 6-8 weeks; weight, $25 \pm 2 \mathrm{~g}$ ) and C57BL/J6 mice (10; male; age, 6-8 weeks; weight, $29 \pm 2 \mathrm{~g}$ ) were purchased from the Department of Experimental Animals (Shanghai Institute of Biological Products, Ministry of Health of China). All mice were kept in specific pathogen-free animal facilities maintained at $18-22^{\circ} \mathrm{C}$ and $50-60 \%$ relative humidity, with a 12-h light/dark cycle and provided ad libitum access to standard rodent chow and filtered water. All experiments were performed in accordance with the guidelines and approved by the Ethics Committee of Soochow University (Suzhou, China; approval no. 201912A341).

Reagents and antibodies. Complete Freund's adjuvant (CFA), incomplete Freund's adjuvant and hypoxanthine-aminopterin-thymidine (HAT) selection medium were purchased from Sigma-Aldrich; Merck KGaA. The rabbit anti-mouse antibodies used were as follows: Mouse isotype immunoglobulin (Ig)G (cat. no. 555571), FITC-labeled anti-mouse granulocyte receptor 1 antigen (GR-1; $\mathrm{IgG}_{2 \mathrm{~b}}$; cat. no. 553127), FITC-labeled anti-mouse CD11b ( $\mathrm{IgG}_{2 \mathrm{~b}}$; cat. no. 553310), phycoerythrin (PE)-labeled anti-mouse CD23 ( $\mathrm{IgG}_{2 \mathrm{a}}$; cat. no. 561773), PE-labeled anti-mouse CD21( $\operatorname{IgG}_{2 \mathrm{~b}}$; cat.no. 552957), PE-labeled anti-mouse CD86( IgG $_{2 \mathrm{a}}$; cat.no.561963),PE-labeled anti-mouse CD80 ( $\operatorname{IgG}_{2 \mathrm{a}}$; cat. no. 561955), FITC-labeled anti-mouse CD11c ( $\mathrm{IgG}_{1}$; cat. no. 561045), PE-labeled mouse IgG (cat. no. 555988), PE-labeled rat anti-mouse IgG1 (cat. no. 562027) and allophycocyanin-labeled anti-mouse B220 ( $\operatorname{IgG}_{2 \mathrm{a}}$; cat. no. 561880). All antibodies were purchased from BD Pharmingen.
Generation and characterization of anti-human B7-1 mAbs. The hybridoma cell line from Shi et al (12) has been observed to secrete anti-human B7-1 antibodies. To generate anti-human B7-1, BALB/c mice were immunized with L929/B7-1 cells $\left(10^{7}\right.$ cells in $100 \mu \mathrm{l}$ PBS) that were pretreated with $10 \mu \mathrm{g} / \mathrm{ml}$ mitomycin (Sigma-Aldrich; Merck KGaA) for $2 \mathrm{~h}$ at $37^{\circ} \mathrm{C}$, by subcutaneous injection into the right flank in conjunction with a separate injection of $400 \mu \mathrm{l}$ CFA. Mice then received three intraperitoneal injections of the cells/CFA at 1-week intervals. Mice were anesthetized (1\% sodium pentobarbital; $50 \mathrm{mg} / \mathrm{kg}$ body weight) 4 days after the final injection and euthanized by cervical dislocation. The spleen was removed by opening the abdominal cavity and a single cell suspension of spleen cells prepared by mechanized homogenization with a syringe filled with PBS, filtration through a filter screen (200 mesh), centrifugation of the suspension $\left(233 \mathrm{x} \mathrm{g}\right.$ for $8 \mathrm{~min}$ at $\left.4^{\circ} \mathrm{C}\right)$ and removal of the supernatant. These cells were then fused with murine myeloma SP2/0 cells using standard protocols $(13,14)$. The resulting hybridomas were subsequently cultured at $37^{\circ} \mathrm{C}$ for 10 days in HAT selection medium. From the successful cultures, supernatants were evaluated for antigen (B7-1) recognition. In brief, L929/B7-1 cells were incubated with the supernatant at $4^{\circ} \mathrm{C}$ for $45 \mathrm{~min}$, then stained with PE-labeled rat anti-mouse $\operatorname{IgG} 1(1: 200)$ at $4^{\circ} \mathrm{C}$ for $30 \mathrm{~min}$. FACS (Calibur system; BD Cell Quest Pro software; version 6.0; BD Biosciences) was used in order to analyze the stained cells. L929/B7-1 cells were also stained with PE-labeled rat anti-mouse IgG1 (1:200) as a negative control.

The specific 4E5 mAb was purified from BALB/c mouse ascites using Protein G-sepharose CL4B affinity columns (GE Healthcare) following the manufacturer's protocols. Female $\mathrm{BALB} / \mathrm{c}$ mice were intraperitoneally injected with pristane (0.5 ml; Sigma-Aldrich; Merck KGaA) and 1 week later, mice were injected with a specific hybridoma line (intraperitoneally; $1 \times 10^{7}$ total cells/mouse). Mice were then injected with an equal volume of a 1:1 (v/v) mixture of pristane and Freund's incomplete adjuvant. After a period of 1 week, which facilitated fluid accumulation in the abdomen (15), the ascites in each mouse were extracted with a syringe and processed using CL4B affinity column purification. The antibody was eluted with $\mathrm{pH} 2.8$ glycine-hydrochloric acid mixture and the concentration was estimated spectrophotometrically. This was calculated as protein concentration $(\mathrm{mg} / \mathrm{ml})=[$ optical density at $\left.280 \mathrm{~nm}\left(\mathrm{OD}_{280}\right) \times 1.55\right]-\left(\mathrm{OD}_{260} \mathrm{x} 0.76\right)$. The purified antibody was then conjugated with PE using standard protocols (16). Flow cytometry was subsequently used to verify the recognition of the B7-1 antigen by the clone 4E5 mAb with L929/mock, L929/B7-1, Daudi and Raji cells, as well as naive BALB/c mouse splenocytes, and performed as described earlier.

Induction of the murine LN model of cGVHD and $4 E 5$ antibody treatment. Female BALB/c mice were mated with male $\mathrm{C} 57 \mathrm{BL} / \mathrm{J} 6$ mice to obtain $\mathrm{F}_{1}$ generations. When $\mathrm{F}_{1}$ hybrids reached the age of 6-8 weeks, the mice (all females selected) were randomly allocated into four groups: Normal control group (Mock, mice did not receive any treatment), model group (MG, cGVHD was induced in the mice), 4E5-treated group (4E5, cGVHD was induced in the mice and they were treated with 4E5) and a random IgG-treated group (IgG, mice cGVHD was induced in the mice and they were treated with 
$\operatorname{IgG}$ ), with 15 mice in each group. Excluding the Mock mice, all other F1 hybrids were used as recipients of female BALB/c donor cells.

To prepare the cells for each injection, two naive female $\mathrm{BALB} / \mathrm{c}$ mice were anesthetized and euthanized using cervical dislocation. After death, the thymus, spleen and axillary lymph nodes of each mouse were recovered and single-cell suspensions were prepared by mechanical homogenization with a syringe filled with PBS, filtering through a filter screen (200 mesh), centrifuging the suspension (233 x g for $8 \mathrm{~min}$ at $4^{\circ} \mathrm{C}$ ) and removing the supernatant PBS. Then these single-cell suspensions of different organs from two mice were mixed together and counted [following standard treatments to remove contaminating erythrocytes as required (12)]. In each case, four individual intravenous injections were performed at 3-day intervals and a $100 \mu \mathrm{l}$ volume of the solution, containing $5 \times 10^{7}$ cells $/ 100 \mu$ of the mixture of fresh donor cells, was injected into each recipient by tail vein. In the 4E5-treated mice, 4E5 mAb (10 mg/kg weight) diluted in PBS, was injected intravenously into the tail on days $15,17,19,21$, 44 and 74 after the first lymphocyte injection. This dose was selected based upon previous work reported by Shi et al (12). The IgG-treated mice were treated in parallel with mouse isotype IgG (BD Pharmingen; BD Biosciences). From 2 weeks after the first lymphocyte inoculation, mice received intraperitoneal anesthesia (1\% sodium pentobarbital; $50 \mathrm{mg} / \mathrm{kg}$ body weight) and $100 \mu \mathrm{l}$ of blood was drawn from the retro-orbital plexus every 30 days. Serum was isolated and frozen at $-80^{\circ} \mathrm{C}$ for subsequent analyses of autoantibodies. At the same time as the blood was collected, urine from each mouse was also collected, by pressing the mouse bladder and inserting a syringe into the urethra, for analysis of potential proteinuria. In all cases, urine and blood were collected at $10 \mathrm{am}$ on the experimental day. At 12 weeks after the final inoculation, all mice were euthanized by intraperitoneal injections of $2 \%$ pentobarbital (120 mg/kg body weight) and death was verified using cervical dislocation. Tissues (including spleen and kidney) were harvested for subsequent analysis.

Immune response evaluated by flow cytometry. A total of 5 mice were selected randomly from each group at 3 weeks after the first lymphocyte injection and their splenocytes were isolated as mentioned above. After counting, distinct sets of $10^{7}$ splenocytes were incubated with a specific fluorochrome-conjugated antibody (GR-1,1:500; CD11b, 1:500; CD23, 1:200; CD21, 1:200; CD86, 1:200; CD80, 1:200; CD11c, 1:500 or B220, 1:200) for $30 \mathrm{~min}$ on ice and washed in PBS ( $\mathrm{pH}$ 7.4) for $30 \mathrm{~min}$ at room temperature. All samples were then analyzed using flow cytometry as mentioned above with analysis using Cell Quest Pro software (BD Biosciences). The major APC populations were macrophages, dendritic cells and granulocytes, which were pre-gated based on the APC activation markers GR-1, CD11b and CD11c in the present study.

Anti-nuclear antibody (ANA) and anti-double-stranded DNA (anti-dsDNA) measurements. To measure the levels of ANA and anti-dsDNA in isolated sera, immunofluorescent staining was performed using an ANA analysis kit (cat. no. YZB/Jing 1373-2009) and a daDNA analysis kit (cat. no. YZB/Jing 1372-2009, Beijing H\&J NovoMed, Co., Ltd.) following the manufacturer's protocol. Sera were diluted (1:100 in PBS) and placed on cell-bearing glass slides containing ANA or dsDNA antigen for incubation (30 $\mathrm{min}$ at room temperature) in a humidified chamber. After being washed gently with PBS, the presence of any ANA or anti-dsDNA was determined using FITC-conjugated goat anti-mouse IgG antibodies with incubation for $30 \mathrm{~min}$ in the dark. Slides were washed again with PBS, air-dried and then sealed. Images were captured using a fluorescence microscope (Olympus Corporation). Levels of the autoantibodies were quantified indirectly using measurements of fluorescence intensity assessed in a blinded manner by three individuals using Image-Pro Plus software version 5.0 (BioRad Laboratories, Inc.). Intensities were then reported based using a semi-quantitative scale: Absent to mild (low) and moderate to very severe (high).

Proteinuria measurement. The fresh urine collected from each mouse was evaluated using Albustix urine dip sticks (Bayer AG), following the manufacturer's protocol. The extent of proteinuria was scored in a blinded manner by three individuals. Scores were reported as follows: Complexes absent $(-)$, or present at mild $(+)$, moderate $(++)$, severe $(+++)$ or very severe $(++++)$ intensity.

Histopathology. A section from each mouse kidney dissected after mouse death was fixed in $10 \%$ buffered formalin for $2 \mathrm{~h}$ at room temperature and then embedded in paraffin. Sections (5 $\mu \mathrm{m})$ were then prepared and stained with hematoxylin and eosin for $10 \mathrm{~min}$ at room temperature. The stained sections were then examined by light microscopy in a blinded manner.

A second section $(100 \mathrm{~nm})$ of each kidney was fixed in $2.5 \%$ glutaraldehyde buffer ( $\mathrm{pH} 7.4$ ) for $2 \mathrm{~h}$ at room temperature, washed twice with PBS for 15 min and dehydrated using gradient dilutions of acetone (70\% acetone for $15 \mathrm{~min}, 80 \%$ for $15 \mathrm{~min}$, $90 \%$ for $15 \mathrm{~min}$ and $100 \%$ twice for $10 \mathrm{~min}$ ). Dehydration of samples was then performed using liquid $\mathrm{CO}_{2}$. Samples were then sputter-coated with gold and examined using an H-800 transmission electron microscope (Hitachi, Ltd.) (17).

Detection of immune complexes in kidney tissue. The remaining parts of the kidney samples were frozen in optimal cutting temperature medium (Thermo Fisher Scientific, Inc.) and cut into $10-\mu \mathrm{m}$ sections, which were air-dried and fixed in acetone at $-20^{\circ} \mathrm{C}$ for $20 \mathrm{~min}$. After being washed in PBS, specimens were incubated with FITC-conjugated goat anti-mouse $\operatorname{IgG}\left(1: 100\right.$ in PBS) for $30 \mathrm{~min}$ at $37^{\circ} \mathrm{C}$. Samples were then washed with PBS, air-dried and examined using a fluorescence microscope (Olympus Corp.). Each sample was scored for fluorescence intensity in a blinded manner by three individuals. Scores were reported as follows: Complexes absent $(-)$, or present at mild $(+)$, moderate $(++)$, severe $(+++)$ or very severe $(++++)$ intensity.

Statistical analysis. All values are expressed as the mean \pm standard deviation. The statistical significance of differences in values and frequencies between groups was evaluated using Student's t-tests (2 groups) or analysis of variance with Tukey's post-hoc test ( $>2$ groups). All analyses were performed using SPSS 19.0 software (IBM, Corp.). $\mathrm{P}<0.05$ was considered to indicate a statistically significant difference. 


\section{Results}

Generation and characterization of anti-human B7-1 mAbs. Based upon previously established procedures (12), a novel mAb targeting human B7-1, 4E5, was generated (isotype IgG1). The flow cytometry results showed that cells were 97.8\% positive in the L929/B7-1 line, $98.5 \%$ in the Daudi cell line and $98.7 \%$ positive in the Raji cell line, (Fig. 1). As the spleen contains several cell types, the spleen cells were only $46.9 \%$ positive. These results indicated that $4 \mathrm{E} 5 \mathrm{mAb}$ was able to recognize B7-1 not only on human cells (including L929/B7-1) but also on mouse splenocytes.

$4 E 5 \mathrm{mAb}$ reduces the expression of activation markers on mouse splenocytes. The expression of CD11b, CD11c and GR1 activation markers on APC cells was higher among the mouse splenocytes from the MG mice compared with that on cells from the Mock mice, indicating that the spleen cells were abnormally activated. By contrast, the frequency of the expression of each marker on cells from the 4E5-treated mice was significantly lower compared with that on cells from MG mice (Fig. 2, $\mathrm{P}<0.05$ ). There was no significant difference in the expression levels of these markers between cells from $\mathrm{MG}$ mice and those from IgG control mice, suggesting that the activation of APC cells in the spleens of mice that received 4E5 was inhibited. The expression of the activation markers CD80 and CD86 on B220+ B-cells from the 4E5-treated mice was also significantly lower compared with that on B-cells from MG mice (Fig. 3, $\mathrm{P}<0.05$ ). These results suggested that $4 \mathrm{E} 5 \mathrm{mAb}$ may suppress immune responses that are normally induced by cGVHD.

$4 E 5 \mathrm{mAb}$ treatment reduces the production of ANA and anti-dsDNA. ANA and anti-dsDNA are cGVHD-induced lupus autoantibodies (18). To assess the severity of LN, the levels of each antibody in the sera were evaluated (Fig. 4). The results demonstrated that at 3 months after the initiation of the cell injections, $30 \%$ of the MG mice and $10 \%$ of the 4E5-treated mice exhibited high levels of ANA antibodies $(\mathrm{P}<0.05$, Table I). At the 4-month time-point, $90 \%$ of the $\mathrm{MG}$ mice and $50 \%$ of the 4E5-treated mice exhibited high levels of ANA antibodies $(\mathrm{P}<0.05)$. At 3 months, $40 \%$ of the MG mice and $10 \%$ of the 4E5-treated mice exhibited high levels of circulating anti-dsDNA antibodies $(\mathrm{P}<0.05)$. At 4 months, $100 \%$ of the MG mice and $40 \%$ of the $4 \mathrm{E} 5$-treated mice expressed high levels of anti-dsDNA antibodies $(\mathrm{P}<0.05)$. No significant differences were indicated in the amount of serum ANA and anti-dsDNA antibodies at either time-point between the MG mice and IgG control mice. ANA and anti-dsDNA antibodies were not identified in the serum of the mock mice at any time-point.

$4 E 5 \mathrm{mAb}$ treatment reduces the incidence of proteinuria. Proteinuria is a marker of renal lesions, and in the present study, it was used as a criterion for the successful induction of the LN model. Analysis of the urine collected monthly following the initiation of lymphocyte inoculations indicated that proteinuria appeared later in the 4E5 treatment group and was less common compared with the frequencies in MG mice (Table II, $\mathrm{P}<0.05$ ). At 3 months after initiation of inoculation,
$50 \%$ of MG mice and none of the 4E5-treated mice exhibited high proteinuria (moderate to very severe; data not shown). The frequency of high proteinuria remained higher in MG mice $(100 \%)$ at 4 months after initiation of the inoculations. By contrast, $50 \%$ of the 4E5-treated mice developed high proteinuria at this time-point. The frequency of proteinuria was not significantly different between the MG mice and IgG control mice and no proteinuria was present in the mock mice at any time-point.

Effects of $4 E 5 \mathrm{mAb}$ treatment on the formation of renal lesions. Histological analysis revealed that kidneys from the MG mice exhibited a compensatory increase in the glomerular volume at 4 months after the initiation of inoculation. The analysis also revealed leukocytic infiltration in perivascular and internal areas, as well as endothelial and mesangial hypercellularity. By contrast, specimens from 4E5-treated mice exhibited slight histopathological changes, including glomerular enlargement and minor congestion of the glomerular vasculature (Fig. 5A). The IgG control mice also demonstrated a number of histological changes compared with mock mice.

Effects of $4 E 5$ mAb treatment on immune complex deposition. Fluorescence analysis of kidney sections from the MG mice at 4 months following the initiation of the inoculations revealed a granular linear staining pattern of $\operatorname{IgG}$ deposits along the glomerular capillary loops, indicating that immune complexes were deposited in/on the loops of glomeruli. Although the fluorescence intensity of mice treated with 4E5 decreased significantly at the same time-point compared with MG group $(\mathrm{P}<0.05)$, no glomerulonephritis was observed and significant differences in the levels of immune complexes between the MG mice and IgG control mice were indicated at 4 months after the initiation of the inoculations (Table III; Fig. 5B). No immune complexes were observed in mock mice at 4 months after the initiation of the inoculations.

Effects of $4 E 5$ mAb treatment on renal ultrastructure. TEM analysis demonstrated that in the kidneys of the MG and IgG control mice, electron-dense deposits were localized in subepithelial lesions of the glomerular basement membrane that were segmental and thickened. These deposits were also observed in visceral epithelial cells that exhibited effaced foot processes (humps). By contrast, in the glomerulus from 4E5-treated mice, the basement membrane layer was clear and intact and there were fewer, smaller 'humps' than in the MG group (Fig. 5C). No abnormal renal ultrastructure was indicated in the kidneys isolated from mock mice.

\section{Discussion}

cGVHD, which is induced in recipient $\mathrm{F} 1$ hybrid mice following the inoculation of parental lymphocytes, resembles SLE with autoantibody production and glomerulonephritis (19). cGVHD is a sex-biased GVHD model in which the female donor makes the female host more vulnerable to SLE than a male (20-22). cGVHD has been revealed to be due to donor alloreactive $\mathrm{CD} 4^{+} \mathrm{T}$-cell activation of host B-cells (23) and is characterized by lymphocyte proliferation, the production of autoantibodies that resemble SLE 


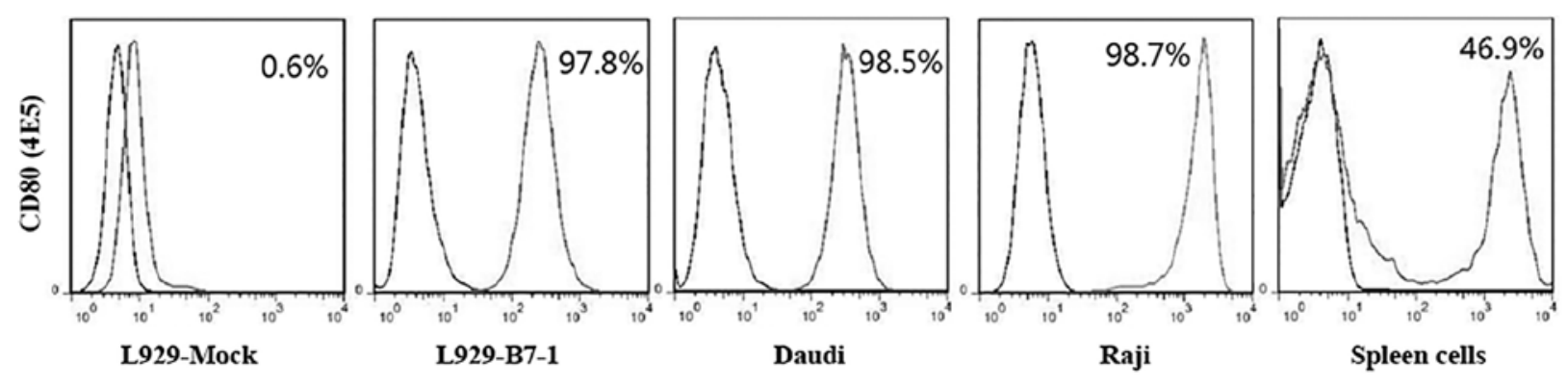

Figure 1. Histograms of cells stained with 4E5. Characterization of mouse anti-human B7-1 monoclonal antibody 4E5 using flow cytometry. Analyses suggested that 4E5 was able to recognize B7-1 on the L929 (B7-1), Daudi, Raji and mouse spleen cells, but not the L929-mock cells. Representative frequency plots are presented.
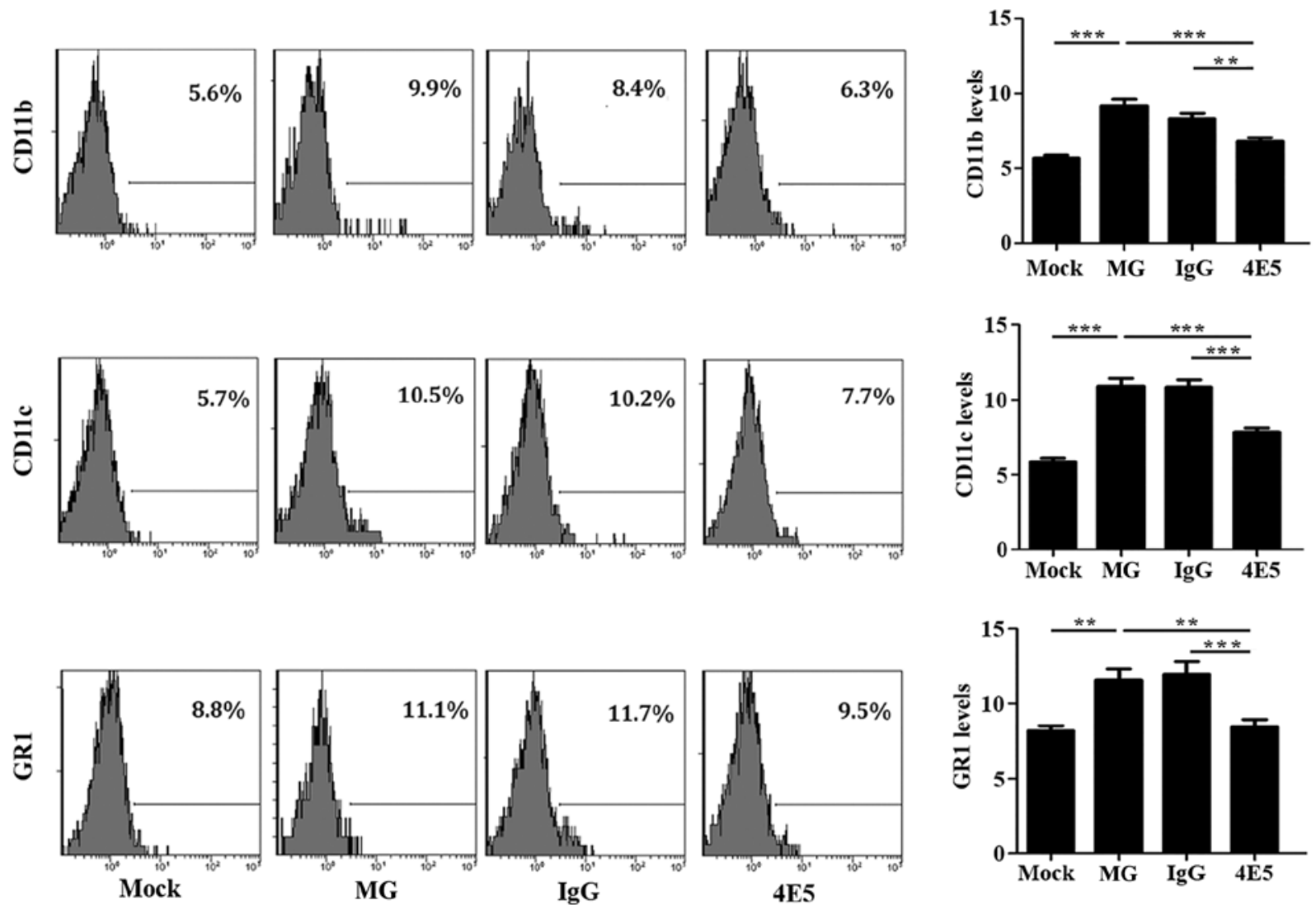

Figure 2. Effects of 4E5 on the activation marker expression levels in antigen-presenting cells. Expression of CD11b, CD11c and GR1 on isolated splenocytes was evaluated using flow cytometry. The expression of each of the markers on cells from 4E5-treated mice was significantly lower than that on cells of the model control mice. Representative histograms are provided. Values in the bar graphs are expressed as the mean \pm standard deviation ( $\mathrm{n}=5$ per group at 3 weeks). ${ }^{* *} \mathrm{P}<0.01,{ }^{* * *} \mathrm{P}<0.001$. GR1, granulocyte receptor 1 antigen; Ig, immunoglobulin; MG, model group.

and serious renal pathology that is mediated by immune complexes. The pathological characteristics mentioned above are similar to those in human SLE; furthermore, it has a rapid onset ( 2 months) and is easy to reproduce with a low cost (24). The most commonly used model of SLE worldwide is the MRL/lpr mouse model (25). These mice were produced by a series of complex hybridizations to the 12th generation from a number of different strains of mice, including LG/J, AKR/J, C3H/D and C57BL/6. The Fas gene of these mice became mutated and the lymphoproliferative gene appeared, leading to T-cell proliferation and lymph node swelling, so that the autoreactive lymphocytes are not eliminated. The symptoms of this model are similar to those of human SLE, which is characterized by the presence of ANA, anti-dsDNA, anti-single stranded DNA and other auto-antibodies. The disadvantage of this model is that it is expensive to create, therefore it was not used in the present study. In future studies, this model should be used to confirm the results of the present study.

B7 molecules (including B7-1 and B7-2) are important co-stimulatory molecules, which may promote or inhibit T-cell activation, proliferation and differentiation, depending on the interactions with the receptors CD28 and CTLA-4 (26-29). B7-CD28 co-stimulatory signals serve important roles in SLE 

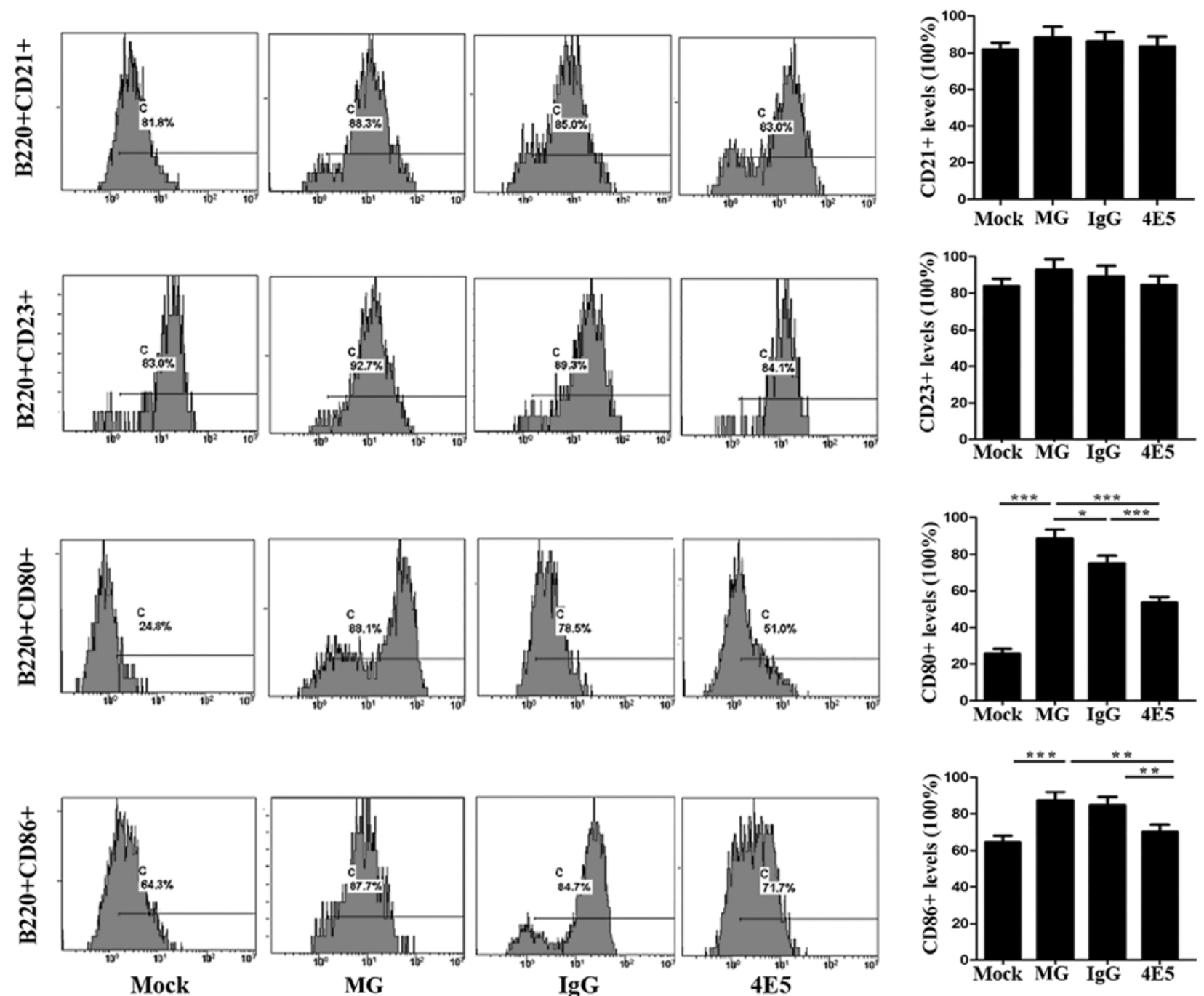

Figure 3. Effects of 4E5 on the expression of B220+ B-cells activation markers. Expression of CD21, CD23, CD80 and CD86 on B220+ B-cells from spleens were measured using flow cytometry. The expression of CD80 and CD86 on cells from 4E5 mice was significantly lower than on cells from MG mice. Representative frequency plots are provided. Values in the bar graphs are expressed as the mean \pm standard deviation ( $\mathrm{n}=5$ per group at 3 weeks). ${ }^{*} \mathrm{P}<0.05$, ${ }^{* * *} \mathrm{P}<0.01,{ }^{* * * *} \mathrm{P}<0.001$. Ig, immunoglobulin; MG, model group.

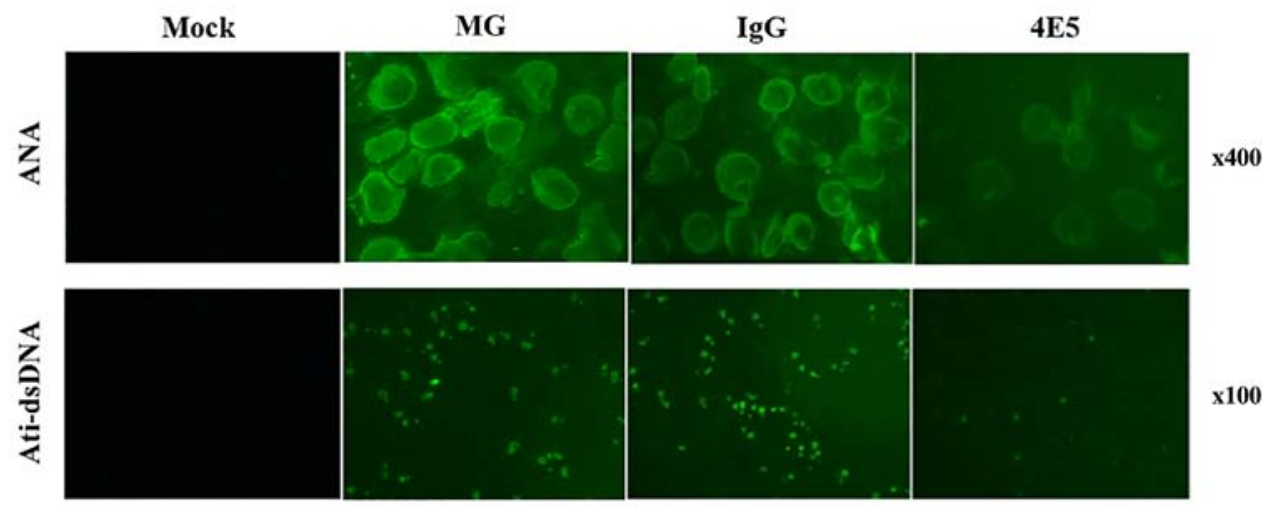

Figure 4. Effects of 4E5 on serum ANA and anti-dsDNA levels at 4 months after initial inoculation. Murine sera were collected monthly for evaluation of ANA (magnification, x400) and anti-dsDNA (magnification, x100) levels. Representative fluorescent images from sera of mice at the 4-month time-point after the initial inoculation are provided. dsDNA, double-stranded DNA; ANA, anti-nuclear antibody; MG, model group.

occurrence/development. It has previously been indicated that preferential expression of B7 on B-cells is essential for anti-DNA autoantibody production in patients with SLE (30).
Bijl et al (31) revealed that the expression of CD86 on CD19+ B-cells was increased and associated with disease activity, B-cell activation and levels of anti-dsDNA in patients with 
Table I. Serum ANA and anti-dsDNA positivity at 3 and 4 months after initiation of inoculations.

\begin{tabular}{|c|c|c|c|c|}
\hline Time-point/autoantibody & Mock & MG & IgG-treated & 4E5-treated ${ }^{\mathrm{a}}$ \\
\hline \multicolumn{5}{|l|}{3 months } \\
\hline ANA & $0(0)$ & $3(30)$ & $4(40)$ & $1(10)^{a}$ \\
\hline Anti-dsDNA & $0(0)$ & $4(40)$ & $4(40)$ & $1(10)^{\mathrm{a}}$ \\
\hline \multicolumn{5}{|l|}{4 months } \\
\hline ANA & $0(0)$ & $9(90)$ & $9(90)$ & $5(50)^{a}$ \\
\hline Anti-dsDNA & $0(0)$ & $10(100)$ & $9(90)$ & $4(40)^{a}$ \\
\hline
\end{tabular}

${ }^{a} \mathrm{P}<0.05$ vs. MG group. Values are expressed as $\mathrm{n}(\%)$ (total $\mathrm{n}=10$ mice per group). ANA, anti-nuclear antibody; dsDNA, double-stranded DNA; Ig, immunoglobulin; MG, model group.

Table II. Comparison of proteinuria status in mice at 4 months after initiation of inoculations.

\begin{tabular}{lccccc}
\hline Group & - & + & ++ & +++ & ++++ \\
\hline Mock & 7 & 3 & 0 & 0 & 0 \\
MG & 0 & 0 & 4 & 5 & 1 \\
IgG-treated & 0 & 0 & 3 & 6 & 1 \\
4E5-treated $^{\text {a }}$ & 1 & 4 & 5 & 0 & 0
\end{tabular}

${ }^{\mathrm{a}} \mathrm{P}<0.05$ vs. MG group. Values are expressed as $\mathrm{n}$ (total $\mathrm{n}=10$ mice per group). The proteinuria status was defined as follows: Absent, (-); mild, $(+)$; moderate, $(++)$; severe, $(+++)$; and highly severe, $(++++)$. Ig, immunoglobulin; MG, model group.

SLE. The percentage of $\mathrm{CD}^{+} 0^{+}$cells in the large activated B-cell $\left.\left(\mathrm{CD}^{+}\right)^{+}\right)$subset of an SLE patient population was also significantly higher compared with subset populations from normal controls and patients with allergies (31). Folzenlogen et al (32) demonstrated that the B7 protein family may reflect immunologic dysregulation in patients with autoimmune diseases and may also indicate a state of increased B-cell activity and hypergammaglobulinemia that occurs during active SLE. Laurent et al (33) demonstrated that a CD28 blockade prevented the development of $\mathrm{LN}$ in NZB/NZW) $\mathrm{F} 1$ mice, which have typical lupus symptoms and are one of the most recognized animal models of lupus nephritis. In the present study, flow cytometry revealed that the expression of activation markers CD80 and CD86 on B220 ${ }^{+}$B-cells in the MG group were significantly higher compared with those in the Mock group.

A number of therapies that block or activate co-stimulation molecules have been indicated to be efficient for the treatment of autoimmune diseases. Inhibiting the B7/CD28 co-stimulatory pathways using anti-B7 antibodies has been revealed to promote corneal allograft survival by inhibiting $\mathrm{CD}^{+}{ }^{+} \mathrm{T}$-cell secretion of interferon- $\gamma$, inhibiting further cellular immune responses and inflammatory reactions (34). Another study demonstrated that anti-CD80 ${ }^{+}$or anti-CD86 mAb infusion was effective in preventing GVHD-associated mortality by inhibiting donor $\mathrm{CD}^{+}$or $\mathrm{CD}^{+} \mathrm{T}$-cell expansion in mice (35). Other avenues of investigation have examined the potential use of CTLA-4 as an immune checkpoint to inhibit T cell
Table III. Comparison of fluorescence intensity in the mice at 4 months after initiation of inoculations.

\begin{tabular}{llllll}
\hline Group & - & + & ++ & +++ & ++++ \\
\hline Mock & 5 & 5 & 0 & 0 & 0 \\
MG & 0 & 0 & 5 & 3 & 2 \\
IgG & 0 & 0 & 5 & 2 & 3 \\
4 E5 $^{\text {a }}$ & 2 & 3 & 5 & 0 & 0 \\
\hline
\end{tabular}

${ }^{a} \mathrm{P}<0.05$ vs. $\mathrm{MG}$ group. Values are expressed as $\mathrm{n}$ (total $\mathrm{n}=10$ mice per group). The fluorescence intensity was rated as follows: Absent, (-); mild, (+); moderate, $(++)$; severe, $(+++)$; and highly severe, $(++++)$. $\mathrm{Ig}$, immunoglobulin; MG, model group.

activation (36). CTLA-4 Ig is a soluble protein that is composed of an extracellular portion of CTLA-4 and an $\mathrm{F}_{\mathrm{c}}$ fragment of $\mathrm{IgG}_{1}$ (37). The essential component of Abatacept is CTLA-4 Ig, which was approved by the US Food and Drug Administration in December 2005 for the treatment of rheumatoid arthritis. Abatacept therapy has been demonstrated to be successful in murine SLE models and in early human clinical trials (38). In the previous study, it was observed that the clinical effects of Abatacept provided a possible benefit in patients with refractory disease, particularly articular or cutaneous involvement requiring medium- to high-dose corticosteroids (39). Previous studies have also indicated that CTLA4-Ig was more effective than cyclophosphamide in preventing glomerular sclerosis and tubular damage in murine SLE models $(39,40)$.

In the present study, a mAb targeting the human CD80 molecule, 4E5, was successfully generated. This mAb was observed to not only recognize human CD80 on a variety of cells but also mouse splenocyte CD80. DNA sequencing analysis of the mouse CD80 complementary DNA has revealed that the mouse CD80 gene is closely associated with the human CD80 gene and shares a $63 \%$ identity in the protein-coding region (41). 4E5 was applied to the $\mathrm{LN}$ model that was induced by cGVHD and the present results demonstrated that 4E5 was able to prevent the development of cGVHD-induced lupus, as well as significantly inhibit immune-cell activation and autoantibody production. The onset of proteinuria, renal histopathologic changes and immune complex deposition in the kidneys were also inhibited. The expression of CD11b, CD11c 


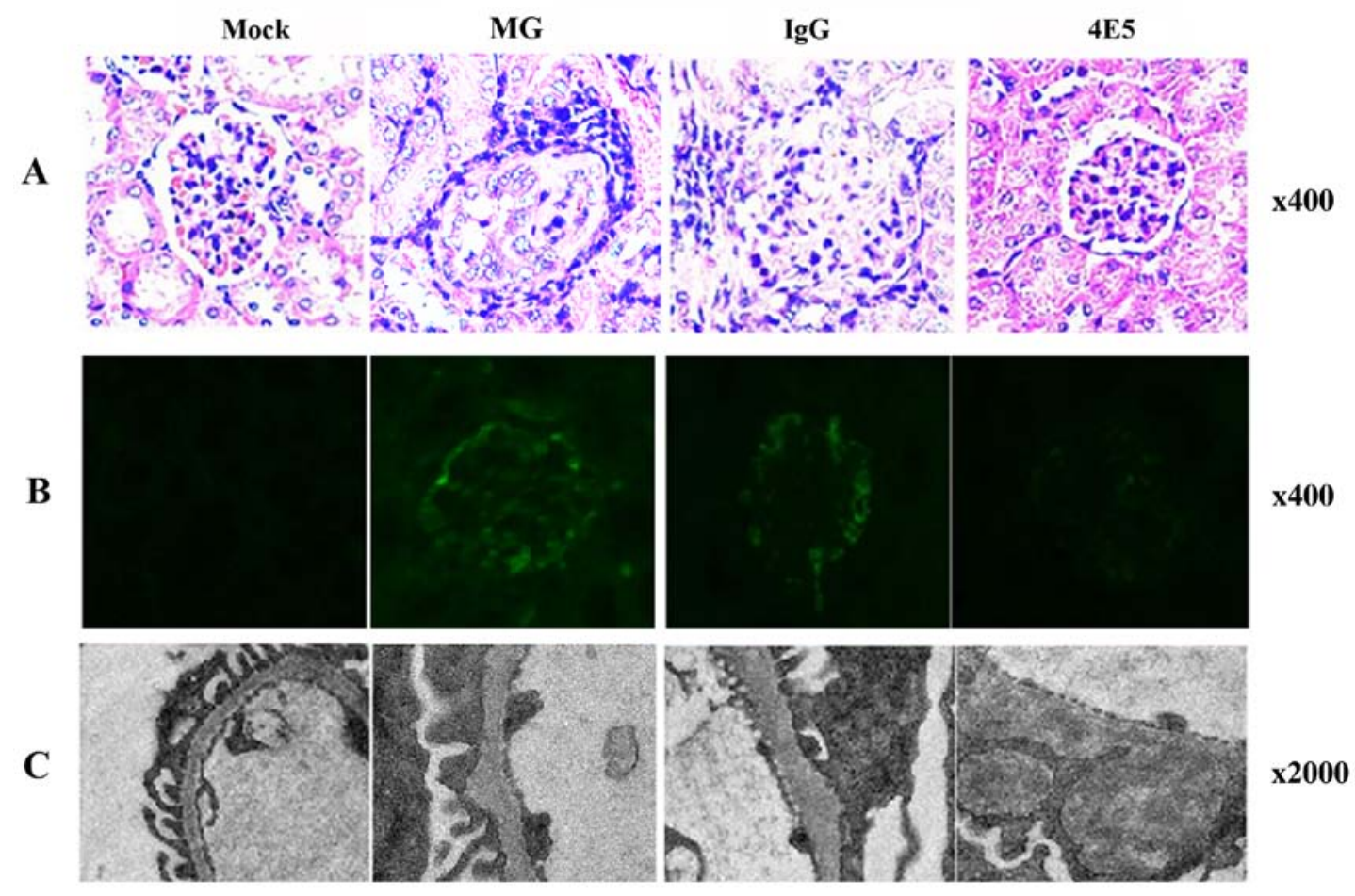

Figure 5. Analysis of kidneys at 4 months after initiation of inoculations. (A) H\&E staining was used to evaluated the kidneys. The glomeruli of MG mice exhibited glomerular volume compensatory enlargement and leukocytic infiltration in perivascular and internal areas, as well as endothelial and mesangial cell hyper-cellularity. Only minor changes were noted in the organs of 4E5 mice when compared with mock mice (magnification, x400). (B) Representative fluorescence microscopy images of kidney sections from MG mice exhibited a granular linear staining pattern of IgG deposits along glomerular capillary loops; tissues of 4E5 mice had little-to-no staining intensity, suggesting minimal deposits (magnification, $\mathrm{x} 400$ ). (C) Representative transmission electron microscopy images revealing electron-dense deposits localized in subepithelial lesions of glomerular basement membrane in kidneys of MG mice; in glomeruli of 4E5 mice, the basement membrane layer was clear and intact, the 'humps' were less and smaller than MG group (magnification, $\mathrm{x} 2,000$ ). ANA, anti-nuclear antibody; dsDNA, double-stranded DNA; Ig, immunoglobulin; MG, model group.

and GR1 in spleen cells indicates the activation of macrophages, dendritic cells and granulocytes in the spleen respectively (12). In the present study, the activation of splenocytes (including macrophages, dendritic cells and granulocytes) in 4E5-treated mice was also significantly lower compared with that in the MG mice, suggesting that 4E5 exerted a suppressive effect during the early stages of immune activation.

Owing to their ability to promote the onset of SLE, B-cells are now considered to serve a key role in the pathogenesis of the disease by providing co-stimulatory signals necessary for T-cell activation, cytokine secretion and immune complex deposition. Treatments aimed at B-cells have therefore become a major therapeutic focus (42). In the present study, the expression of activation markers of B220+ B-cells CD86 and CD80 on cells in the 4E5-treated mice were lower compared with those on the cells of control mice, which may indicate a potential use in anti-B-cell therapy for treating SLE. Since T-B cell activation was inhibited and early immune responses were reduced in the cGVHD mice by treatment with the 4E5 $\mathrm{mAb}$, the inhibition of CD80/CD28 signaling may be useful in B-cell-directed therapies against autoimmune diseases, including SLE. The model selected in this present study is characterized by the production of autoantibodies and immune complexes that are able to affect the majority of human organs (43). The autoantibodies are produced by the activated $\mathrm{B}$ cells, and thus, the present study focused on whether B cells were activated, while $\mathrm{T}$ cells were not assessed. However, the T-cell pathway is important and future research should determine its role in SLE. Since proteinuria is a marker of renal lesions and a criterion for determining the induction of a successful LN model, the detection of proteinuria is regarded as an important index for the diagnosis and prognostic evaluation of LN. However, it is easily affected by the compliance of patients (44). A previous study (44) demonstrated that urinary albumin may be used to monitor renal damage due to the following: i) Albumin is the major component of urinary protein; ii) epidemiological data indicated that elevated levels of urinary albumin are associated with the risk of renal and cardiovascular disease; iii) according to the latest guidelines, the level of urinary albumin is one of the bases for the classification of chronic kidney disease. Overall, the determination of urinary albumin level is an important indicator for monitoring the development of nephropathy and should be performed in future experiments $(45,46)$.

The primary cause of renal damage, $\mathrm{LN}$, in patients with SLE is overproduction of pathogenic autoantibodies, including ANA and anti-dsDNA (18). The present study revealed that the production of ANA and anti-dsDNA in 4E5-treated mice was lower compared with that in the MG mice and that the extent of kidney damage, reflected by proteinuria, was also reduced. Although the present study demonstrated that B7-CD28 co-stimulatory signaling was associated with the development of SLE, inhibiting or weakening the signal may reduce the pathological damage associated with the disease. Further exploration of the roles of anti-CD80 antibodies in humans with SLE is required. A number of therapeutic 
strategies for SLE are currently under investigation (47). The novel $4 \mathrm{E} 5 \mathrm{mAb}$ identified in the present study may be useful for immune therapies for the treatment of SLE, as well as the treatment of other autoimmune diseases and potentially in organ transplantation.

\section{Acknowledgements}

Not applicable.

\section{Funding}

This study was supported by the National Natural Science Foundation of China (grant nos. 81802341 and 81373236), the Jiangsu Provincial Medical Youth Talent (grant no. QNRC2016235) and the Suzhou Administration of Science and Technology (grant no. SYS201571).

\section{Availability of data and materials}

The datasets used and/or analyzed during the present study are available from the corresponding author on reasonable request

\section{Authors' contributions}

YHQ and YX designed the experiments and drafted the manuscript. LJS, YZ, LHH, YYW, TMY and YK performed the experiments and analyzed the data. STZ analyzed the data. LJS, YX and STZ revised the manuscript and gave final approval of the version to be published. All authors read and approved the final manuscript.

\section{Ethics and approval and consent to participate}

The present study was approved by the Ethics Committee of Soochow University (Suzhou, China; approval no. 201912A341).

\section{Patient consent for publication}

Not applicable.

\section{Competing interests}

The authors declare that they have no competing interests.

\section{References}

1. Tenbrock K, Juang YT, Kyttaris VC and Tsokos GC: Altered signal transduction in SLE T cells. Rheumatology (Oxford) 46: 1525-1530, 2007.

2. Saxena R, Mahajan T and Mohan C: Lupus nephritis: Current update. Arthritis Res Ther 13: 240, 2011.

3. Caltik A, Demircin G, Bulbul M, Erdogan O, Akyuz SG and Arda N: An unusual case of ANA negative systemic lupus erythematosus presented with vasculitis, long-standing serositis and full-house nephropathy. Rheumatol Int 33: 219-222, 2013.

4. Appleman LJ and Boussiotis VA: T cell anergy and costimulation. Immunol Rev 192: 161-180, 2003.

5. Lenschow DJ, Walunas TL and Bluestone JA: CD28/B7 system of T cell costimulation. Annu Rev Immunol 14: 233-258, 1996.

6. Bretscher P and Cohn M: A theory of self-nonself discrimination. Science 169: 1042-1049, 1970.

7. Bour-Jordan H and Blueston JA: CD28 function: A balance of costimulatory and regulatory signals. J Clin Immunol 22: 1-7, 2002.
8. Suvas S, Singh V, Sahdev S, Vohra H and Agrewala JN: Distinct role of CD80 and CD86 in the regulation of the activation of $B$ cell and B cell lymphoma. J Biol Chem 277: 7766-7775, 2002.

9. Reynolds J, Tam FW, Chandraker A, Smith J, Karkar AM, Cross J, Peach R, Sayegh MH and Pusey CD: CD28-B7 blockade prevents the development of experimental autoimmune glomerulonephritis. J Clin Invest 105: 643-651, 2000.

10. Lewis RM, Armstrong MY, Andre-Schwartz J, Muftuoglu A, Beldotti L and Schwartz RS: Chronic allogeneic disease. I. Development of glomerulonephritis. J Exp Med 128: 653-679, 1968.

11. Sekine H, Watanabe H and Gilkeson GS: Enrichment of anti-glomerular antigen antibody-producing cells in the kidneys of MRL/MpJ-Fas(lpr) mice. J Immunol 172: 3913-3921, 2004.

12. Shi Q, Gao ZY, Xie F, Wang LF, Gu YP, Yang TJ, Huang L, Qian QH and Qiu YH: A novel monoclonal antibody against human CD80 and its immune protection in a mouse lupus-like disease. Int J Immunopathol Pharmacol 24: 583-593, 2011.

13. Zhang GB, Zhou H, Chen YJ, Ge Y, Xie F, Shi Q, Ma HB, Fei M and Zhang XG: Characterization and application of two novel monoclonal antibodies against 2IgB7-H3: Expression analysis of 2IgB7-H3 on dendritic cells and tumor cells. Tissue Antigens 66: 83-92, 2005.

14. Sun WP, Wang FM, Xie F, Wang GQ, Sun J, Yu GH, Qiu YH and Zhang XG: A novel anti-human syndecan-1 (CD138) monoclonal antibody 4B3: Characterization and application. Cell Mol Immunol 4: 209-214, 2007.

15. Kints JP, Manouvriez P and Bazin H: Rat monoclonal antibodies. VII. Enhancement of ascites production and yield of monoclonal antibodies in rats following pretreatment with pristane and Freund's adjuvant. J Immunol Methods 119: 241-245, 1989.

16. Kronick MN: The use of phycobiliproteins as fluorescent labels in immunoassay. J Immunol Methods 92: 1-13, 1986.

17. Han L, Shen L, Zhu Y and Qiu Y: A monoclonal antibody against CD86 and its protection in a murine lupus nephritis model of chronic graft-versus-host disease. Immunopharmacol Immunotoxicol 39: 285-291, 2017.

18. Bruns A, Blass S, Hausdorf G, Burmester GR and Hiepe F: Nucleosomes are major $\mathrm{T}$ and $\mathrm{B}$ cell autoantigens in systemic lupus erythematosus. Arthritis Rheum 43: 2307-2315, 2000.

19. Murphy WJ: Revisiting graft-versus-host disease models of autoimmunity: New insights in immune regulatory processes. J Clin Invest 106: 745-747, 2000.

20. Howie JB and Helyer BJ: The immunology and pathology of NZB mice. Adv Immunol 9: 215-266, 1968.

21. Ka SM, Rifai A, Chen JH, Cheng CW, Shui HA, Lee HS, Lin YF, Hsu LF and Chen A: Glomerular crescent-related biomarkers in a murine model of chronic graft versus host disease. Nephrol Dial Transplant 21: 288-298, 2006.

22. Foster AD, Soloviova K, Puliaeva I, Puliaiev M, Puliaev R, Finkelman F and Via CS: Donor CD8 T cells and IFN-gamma are critical for sex-based differences in donor CD4 T cell engraftment and lupus-like phenotype in short-term chronic graft-versus-host disease mice. J Immunol 186: 6238-6254, 2011.

23. Rus V, Svetic A, Nguyen P, Gause WC and Via CS: Kinetics of Th1 and Th2 cytokine production during the early course of acute and chronic murine graft-versus-host disease. Regulatory role of donor CD8+ T cells. J Immunol 155: 2396-2406, 1995.

24. Bergijk EC, Munaut C, Baelde JJ, Prins F, Foidart JM, Hoedemaeker PJ and Bruijn JA: A histologic study of the extracellular matrix during the development of glomerulosclerosis in murine chronic graft-versus-host disease. Am J Pathol 140: 1147-1156, 1992.

25. Dhaher YY, Chan K, Greenstein BD, de Fougerolles Nunn E, Khamashta MA and Hughes GR: Impaired estrogen priming of progesterone receptors in uterus of MRL/MP-lpr/lpr mice, a model of systemic lupus erythematosus (SLE). Int $J$ Immunopharmacol 22: 537-545, 2000.

26. Kuroda Y, Akaogi J, Nacionales DC, Wasdo SC, Szabo NJ, Reeves WH and Satoh M: Distinctive patterns of autoimmune response induced by different types of mineral oil. Toxicol Sci 78: 222-228, 2004.

27. Kim J, Park K, Kim HJ, Kim J, Kim HA, Jung D, Kim HJ, Choi HJ, Choi SY, Seo KW, et al: Breaking of CD8+ T cell tolerance through in vivo ligation of CD40 results in inhibition of chronic graft-versus-host disease and complete donor cell engraftment. J Immunol 181: 7380-7389, 2008.

28. Kothlow S, Morgenroth I, Tregaskes CA, Kaspers B and Young JR: CD40 ligand supports the long-term maintenance and differentiation of chicken B cells in culture. Dev Comp Immunol 32: 1015-1026, 2008. 
29. Leitner J, Grabmeier-Pfistershammer K and Steinberger P Receptors and ligands implicated in human $\mathrm{T}$ cell costimulatory processes. Immunol Lett 128: 89-97, 2010.

30. Nagafuchi H, Shimoyama Y, Kashiwakura J, Takeno M, Sakane T and Suzuki N: Preferential expression of B7.2 (CD86), but not B7.1 (CD80), on B cells induced by CD40/CD40L interaction is essential for anti-DNA autoantibody production in patients with systemic lupus erythematosus. Clin Exp Rheumatol 21: 71-77, 2003.

31. Bijl M, Horst G, Limburg PC and Kallenberg CG: Expression of costimulatory molecules on peripheral blood lymphocytes of patients with systemic lupus erythematosus. Ann Rheum Dis 60: 523-526, 2001.

32. Folzenlogen D, Hofer MF, Leung DY, Freed JH and Newell MK Analysis of CD80 and CD86 expression on peripheral blood B lymphocytes reveals increased expression of CD86 in lupus patients. Clin Immunol Immunopathol 83: 199-204, 1997.

33. Laurent L, Le Fur A, Le Bloas RL, Néel M, Mary C, Moreau A, Poirier N, Vanhove B and Fakhouri F: Prevention of lupus nephritis development in NZB/NZW mice by selective blockade of CD28. Eur J Immunol 47: 1368-1376, 2017.

34. Asai T, Choi BK, Kwon PM, Kim WY, Kim JD, Vinay DS, Gebhardt BM and Kwon BS: Blockade of the 4-1BB (CD137)/4-1BBL and/or CD28/CD80/CD86 costimulatory pathways promotes corneal allograft survival in mice. Immunology 121: 349-358, 2007.

35. Blazar BR, Sharpe AH, Taylor PA, Panoskaltsis-Mortari A, Gray GS, Korngold R and Vallera DA: Infusion of anti-B7.1 (CD80) and anti-B7.2 (CD86) monoclonal antibodies inhibits murine graft-versus-host disease lethality in part via direct effects on CD4+ and CD8+ T cells. J Immunol 157: 3250-3259, 1996.

36. Brunner-Weinzierl MC, Hoff $\mathrm{H}$ and Burmester GR: Multiple functions for $\mathrm{CD} 28$ and cytotoxic T lymphocyte antigen-4 during different phases of $\mathrm{T}$ cell responses: Implications for arthritis and autoimmune diseases. Arthritis Res Ther 6: 45-54, 2004.

37. Finck BK, Linsley PS and Wofsy D: Treatment of murine lupus with CTLA-Ig. Science 265: 1225-1227, 1994.

38. Furie R, Nicholls K, Cheng TT, Houssiau F, Burgos-Vargas R, Chen SL, Hillson JL, Meadows-Shropshire S, Kinaszczuk M and Merrill JT: Efficacy and safety of abatacept in lupus nephritis: A twelve-month, randomized, double-blind study. Arthritis Rheumatol 66: 379-389, 2014.
39. Danion F, Rosine N, Belkhir R, Gottenberg JE, Hachulla E, Chatelus E, Pugnet G, Pers YM, Mariette X, Sibilia J, et al: Efficacy of abatacept in systemic lupus erythematosus: A retrospective analysis of 11 patients with refractory disease. Lupus 25: 1440-1447, 2016.

40. Cunnane G, Chan OT, Cassafer G, Brindis S, Kaufman E, Yen TSB and Daikh DI: Prevention of renal damage in murine lupus nephritis by CTLA-4Ig and cyclophosphamide. Arthritis Rheum 50: 1539-1548, 2004.

41. Freeman GJ, Gray GS, Gimmi CD, Lombard DB, Zhou LJ, White M, Fingeroth JD, Gribben JG and Nadler LM: Structure, expression, and $\mathrm{T}$ cell costimulatory activity of the murine homologue of the human B lymphocyte activation antigen B7. J Exp Med 174: 625-631, 1991.

42. Tieng AT and Peeva E: B-cell-directed therapies in systemic lupus erythematosus. Semin Arthritis Rheum 38: 218-227, 2008.

43. Mills JA: Systemic lupus erythematosus. N Engl J Med 330: 1871-1879, 1994.

44. Satoh M, Kumar A, Kanwar YS and Reeves WH: Anti-nuclear antibody production and immune-complex glomerulonephritis in BALB/c mice treated with pristane. Proc Natl Acad Sci USA 92: 10934-10938, 1995.

45. Nagata M, Ninomiya T, Kiyohara Y, Murakami Y, Irie F, Sairenchi T, Miura K, Okamura T and Ueshima H; EPOCH-JAPAN Research Group: Prediction of cardiovascular disease mortality by proteinuria and reduced kidney function: Pooled analysis of 39,000 individuals from 7 cohort studies in Japan. Am J Epidemiol 178: $1-11,2013$.

46. Currie $\mathrm{G}$ and Delles C: Proteinuria and its relation to cardiovascular disease. Int J Nephrol Renovasc Dis 7: 13-24, 2013.

47. Holdsworth SR, Gan PY and Kitching AR: Biologics for the treatment of autoimmune renal diseases. Nat Rev Nephrol 12: 217-231, 2016.

This work is licensed under a Creative Commons Attribution-NonCommercial-NoDerivatives 4.0 International (CC BY-NC-ND 4.0) License. 